\title{
Leak point pressure at different bladder volumes in stress urinary incontinence in women: Comparison between Valsalva and cough- induced leak point pressure
}

\author{
Young Ho Seo, MD; Sun-Ouck Kim, MD; Ho Song Yu, MD; Dongdeuk Kwon, MD
}

Department of Urology, Chonnam National University Medical School, Gwangiu, Korea

Cite as: Can Urol Assoc J 2016;10(1-2):E23-7. http://dx.doi.org/10.5489/cuaj.3329

Published online January 14, 2016.

\section{Abstract}

Introduction: We compared Valsalva leak point pressure (VLPP) in urodynamically proven stress urinary incontinence (SUI) in women at different bladder volumes; examined the relationship between VLPP and cough-induced leak point pressure (CLPP) compared by incontinence severity; and evaluated the influence of bladder volume on each leak point pressure (LPP).

Methods: Women with urodynamically proven SUI who underwent serial VLPP and CLPP measurement at bladder volumes of $150,200,250$, and $300 \mathrm{~mL}$ were included in this study $(\mathrm{n}=228)$. LPP determination was repeated two times in each subject after finishing one series of LPP measurement. LPP at different bladder volumes was compared by subjective symptom severity of Stamey grade.

Results: Patients mean age was $51.3 \pm 7.6$ years (range: $40-65$ years). Stamey grade I, II, and III was assigned to 68 (29.8\%), $102(44.7 \%)$, and $58(25.4 \%)$ patients, respectively. Mean CLPP was higher than VLPP $(p=0.002)$ at every bladder volume. VLPP and CLPP were significantly decreased by the increase of bladder volume $(p=0.001)$. The mean first positive LPPs were significantly lower at higher Stamey grade $(p=0.004)$.

Conclusions: LPP is more frequently induced by cough than by the Valsalva maneuver. VLPP and CLPP decreased significantly with bladder filling and those with severe symptoms of SUI are more likely to have low LPP.

\section{Introduction}

VLPP is defined by the International Continence Society as an intravesical pressure that exceeds the continence mechanism, and which results in a leakage of urine in the absence of a detrusor contraction. ${ }^{1}$ LPP has been recognized as a tool for determining the severity of stress incontinence, the effectiveness of therapy, and the presence of intrinsic sphincter deficiency (ISD), which is clinically important, especially before determining the surgical correction of SUI. ${ }^{2,3}$ The use of VLPP has been suggested when diagnosing type III SUI and it's been reported that $76 \%$ of women with type III SUI showed VLPP value $<60 \mathrm{~cm} \mathrm{H}_{2} \mathrm{O}$; women with a VLPP $>90$ $\mathrm{cm} \mathrm{H}_{2} \mathrm{O}$ had type II SUI in the study. ${ }^{4}$

However, VLPP measurement is still controversial, and the VLPP value can be affected by various factors, such as bladder volume, catheter insertion, catheter size, patient position, and pelvic organ prolapsed. - $^{5}$ Although the measurement of LPP has not been standardized, many clinicians use this technique to test for SUI.

Cough-induced LPP (CLPP) is another way to test for stress incontinence, especially when the measurement of VLPP is impossible because not enough pressure can be produced from the Valsalva maneuver. McGuire et al suggested measuring VLPP first and then switching to CLPP when the VLPP is negative. ${ }^{9}$ It has been reported that CLPP is significantly higher than VLPP in the same women. ${ }^{5}$ Kuo reported in a videourodynamic comparison study between VLPP and CLPP that a lower LPP was observed, measured by VLPP rather than by CLPP to diagnose ISD. The author determined a significant inverse correlation between the severity of incontinence and VLPP, and showed that CLPP was higher than VLPP in the majority $(87.1 \%)$ of the 116 women with SUI. ${ }^{4}$

The volume in the bladder should not affect the VLPP as long as the detrusor pressure is kept at a level that does not affect the urethra. However, progressive lowering of the VLPP measurement in the same subject when the bladder volume increases has been reported in some studies. 6,10 Since there has not been a standardized protocol developed for performance of this test, discrepancy of the value is inevitable. Only a few recently reported data regarding the measurement of this value are available. ${ }^{4,11,12}$

The purpose of this study was to compare the VLPP and CLPP in urodynamically proven SUI women at different bladder volumes to evaluate whether the bladder volume can affect the LPP, to examine the relationship between 
Seo et al.

VLPP and CLPP, and to determine if LPP would be changed by the incontinence severity to evaluate whether the bladder volume can affect the LPP.

\section{Methods}

\section{Subjects and the study design}

A total of 228 women with urodynamically proven SUI who underwent serial VLPP and CLPP measurements at bladder volumes of 150, 200, 250, and $300 \mathrm{~mL}$ between January 2009 and December 2011 were included in this study. The LPP determination was repeated two times in each subject after finishing one series of LPP measurements. LPPs determined at the different bladder volumes were compared by the Stamey grade of subjective symptoms severity. ${ }^{13}$ All patients underwent urological evaluation before treatment, including a comprehensive medical history, physical and neurologic examinations, and urine analysis. The examiner was a very experienced specialist in urology. This study received approval from the local ethics committee. The procedure for this study complied with the guidelines provided by the Declaration of Helsinki.

\section{Exclusion criterio}

Patients were excluded from this analysis according to the following criteria: history of urinary retention with residual urine over $200 \mathrm{~mL} / \mathrm{sec}$; active urinary tract infections and other urologic disease or drug treatment that could have an impact on bladder function and urethral function; patients using alpha-adrenergic receptor agonists or antagonists; patients who had any possible cause of neurogenic bladder; patients who had severe urogenital prolapse (Pelvic Organ Prolapse Quantification stages, 2-4) ${ }^{14}$ and had a history of anti-incontinence surgery or other surgeries that can influence urinary stream; and patients with detrusor overactivity on filling cystometry.

\section{Urodynamic study}

Multichannel urodynamic evaluation according to the standards of the International Continence Society was performed. ${ }^{15}$ Measurement of VLPP was performed with the patient in lithotomy position on an urodynamic table. A compact urodynamic device (Dantec, Denmark) was used. The pressure transducers, zeroed at atmospheric pressure, were leveled at the upper edge of the symphysis pubis and connected to the intravesical and rectal catheter. A threechannel, fluid-filled $8 \mathrm{Fr}$ urethral cystometry catheter was used for every LPP measurement. Residual urine was evacuated. Rectal pressure was measured with a water-filled $8 \mathrm{Fr}$ balloon catheter. The bladder was filled with body-temperature saline at $50 \mathrm{~mL} / \mathrm{min}$. Serial VLPP and CLPP measurements at bladder volumes of 150, 200, 250, and $300 \mathrm{~mL}$ were included in the analysis. The diagnosis of SUI was made if the subject had symptoms of stress incontinence and direct visualization of urine leakage produced by stress without concurrently demonstrable detrusor activity during cystometry after the bladder was filled. Each measurement was repeated two or three times and the lowest value was selected for analysis.

\section{Statistical analyses}

SPSS version 17 for Windows (SPSS, Chicago, IL) was used for statistical analyses. Data were expressed as mean \pm standard deviation (SDs) and the data were analyzed by Chi-square test and repeated measure analysis of variance was performed. A $p$ value $<0.05$ was deemed statistically significant.

\section{Results}

Patients mean age (years), mean parity, and body mass index $\left(\mathrm{BMl} ; \mathrm{kg} / \mathrm{m}^{2}\right.$ ) was $51.3 \pm 7.6$ (range, 40-65), $2.5 \pm 1.9$, and $26.8 \pm 2.8$, respectively. The main incontinence severity of the subjects was Stamey grade II in $102(44.7 \%)$ of the subjects, followed by Stamey grade I in 68 (29.8\%), and Stamey grade III in $58(25.4 \%)$.

The mean value of VLPP and CLPP according to the bladder volume, and LPP according to the Stamey grade are shown in Tables 1 and 2. CLPP was higher than VLPP at every bladder volume $(p=0.001)$ (Table 1$)$. VLPP and CLPP were gradually decreased as the bladder volume increased from $150 \mathrm{~mL}$ to $300 \mathrm{~mL}$, and were inversely correlated with bladder volume $(p=0.001)$. Positive VLPP at the bladder volume of $150,200,250$, and $300 \mathrm{~mL}$ were $76.58 \pm 17.51$, $109.75 \pm 12.89,73.3 \pm 16.96$, and $103.28 \pm 15.63$, respectively. Positive CLPP values at the same respective bladder volumes were $68.64 \pm 17.92,98.29 \pm 20.30,63.98 \pm 16.53$, and $93.94 \pm 17.70$, respectively (Table 1 ).

Both the VLPP and CLPP measurements were affected by Stamey grade. The mean first positive LPPs were significantly lower with high Stamey grade $(p=0.004)$ (Table 2$)$. The mean estimated VLPP in Stamey grade I, II, and III was $85.71 \pm 18.45,77.22 \pm 14.98$, and $63.68 \pm 13.92$, respectively. The mean measured CLPP in Stamey grade I, II, and III was $121.83 \pm 9.92,108.02 \pm 9.32$, and $98.21 \pm 10.31$, respectively.

\section{Discussion}

Presently, we evaluated the relationship between VLPP and CLPP, and the change of LPP with different bladder volumes in SUI women. Mean CLPP was higher than 
Table 1. Estimated leak point pressure by the increase of bladder filling volume

\begin{tabular}{|c|c|c|c|c|c|}
\hline & \multicolumn{4}{|c|}{ Bladder filling volume (mL) } & \multirow{2}{*}{$p$ value } \\
\hline & 150 & 200 & 250 & 300 & \\
\hline CLPP & $109.75 \pm 12.89$ & $103.28 \pm 15.63$ & $98.29 \pm 20.30$ & $93.94 \pm 17.70$ & \multirow{2}{*}{$<0.001$} \\
\hline VLPP & $76.58 \pm 17.51$ & $73.3 \pm 16.96$ & $68.64 \pm 17.92$ & $63.98 \pm 16.53$ & \\
\hline
\end{tabular}

VLPP, and LPP measurement was gradually decreased as the bladder volume increased, which showed the inverse correlation between them. Furthermore, both VLPP and CLPP measurements were affected by symptom severity of SUI. The mean first positive LPP was significantly lower at high Stamey grade. These results suggest that the urinary continence system responds differently to coughing or the Valsalva maneuver because the increased intra-abdominal pressure is higher during coughing than Valsalva. The results of this study also imply that LPP should be checked at the same bladder volume when comparing or predicting the disease entity of patients with SUI with varying degrees of SUI symptoms. This study also shows that basal symptom severity is representative of VLPP and CLPP; we confirmed previous reports that have shown strong correlation between the subjective symptom grade and LPP in these patients. ${ }^{4-6,10}$

McGuire et al introduced the concept of type III incontinence, the most severe form of incontinence of ISD. ${ }^{16}$ They noted that some patients show repeated failure from the retropubic suspension surgery for the correction of SUI and described that patients with failed surgery had a deficient urethral sphincter function characterized by open bladder neck and proximal urethra at rest with minimal or no urethral movement during increased intra-abdominal pressure. ${ }^{16}$ It has been considered that surgical procedures for the correction of SUI with ISD component have a somewhat high incidence of failure rate because of the underlying problem of severe urethral dysfunction. In the setting of the urologic clinic, whether the patient with SUI has ISD or not is an important clinical factor, especially before making a surgical decision, because it can change the operative outcome. Although subjective parameters are important in the diagnosis of ISD, clinicians want to find objective parameters to quantify urethral sphincter function and diagnose ISD. A uniform definition of ISD is presently lacking and tests used to diagnose ISD include low VLPP.
VLPP measurement offers an objective means of assessing urethral function and incontinence, which is the intraabdominal pressure that can overcome urethral resistance and cause urine leakage. ${ }^{17}$ VLPP has been considered as a procedure to determine the severity of symptoms of SUI, the effectiveness of certain types of management, and the diagnosis of ISD component in SUI women. ${ }^{17}$

CLPP can also be used to test for SUI when the measurement of VLPP is impossible. McGuire et al suggested that diagnosis of ISD using LPP could be changed by the test condition, including provocation maneuver. ${ }^{9}$ They reported the different incidence rate of ISD by coughing or the Valsalva maneuver-induced LPP measurement, showing that $16.9 \%$ of women would be diagnosed with ISD measured by CLPP, but $35.6 \%$ of them would be diagnosed with ISD by VLPP when diagnosing ISD using LPP $<65 \mathrm{~cm} \mathrm{H}_{2} \mathrm{O} .{ }^{9}$ Bump et al reported significantly higher CLPP than VLPP in SUI women. ${ }^{18}$ One may hypothesize that an involuntary contraction of the suburethral tissue occurs during vigorous coughing. ${ }^{19}$ During coughing, involuntary isotonic or isometric contraction of the pelvic floor muscle might counteract the force of the suburethral tissue. ${ }^{20}$ The authors explained that CLPP represents the intra-abdominal pressure that exceeds the intrinsic urethral resistance plus the suburethral tissue contraction pressure during coughing, and that a greater CLPP than VLPP means the presence of a sufficient contraction of the pelvic and suburethral tissues during coughing. A recent study investigated the relationship between VLPP and CLPP in women with SUI, and reported good correlation between these parameters and SUI; CLPP was greater than VLPP in $87.1 \%$ of the subjects and equaled the VLPP in $12.9 \%$ of the subjects. ${ }^{4}$

However, it has been reported that LPP decreases with increasing vesical volume. ${ }^{18}$ The progressive lowering of VLPP in the same patients as the bladder volume increased has been reported in urodynamic studies. ${ }^{6,10}$ McLennan et

Table 2. Comparison of the estimated leak point pressure by increasing bladder filling volume and Stamey grade

\begin{tabular}{lcccccccc}
\hline & \multicolumn{9}{c}{ CLPP } \\
\cline { 2 - 9 } Stamey grade & \multicolumn{4}{c}{ Bladder filling volume $(\mathbf{m L})$} \\
\cline { 2 - 10 } & $\mathbf{1 5 0}$ & $\mathbf{2 0 0}$ & $\mathbf{2 5 0}$ & $\mathbf{3 0 0}$ & $\mathbf{1 5 0}$ & $\mathbf{2 0 0}$ & \multicolumn{3}{c}{ BLPP } \\
\hline I & $121.83 \pm 9.92$ & $112.15 \pm 14.91$ & $110.58 \pm 20.73$ & $103.21 \pm 17.55$ & $85.71 \pm 18.45$ & $81.83 \pm 18.46$ & $78.08 \pm 20.24$ & $70.96 \pm 17.47$ \\
II & $108.02 \pm 9.32$ & $103.95 \pm 12.21$ & $98.02 \pm 16.37$ & $93.97 \pm 14.72$ & $77.22 \pm 14.98$ & $73.17 \pm 13.92$ & $68.63 \pm 14.93$ & $64.46 \pm 14.80$ \\
III & $98.21 \pm 10.31$ & $90.68 \pm 15.45$ & $83.37 \pm 17.87$ & $82.16 \pm 17.57$ & $63.68 \pm 13.92$ & $61.63 \pm 14.85$ & $56.74 \pm 13.95$ & $54.16 \pm 14.74$ \\
\hline
\end{tabular}

VLPP: Valsalva leak point pressure $(\mathrm{cmH} 2 \mathrm{O})$; CLPP: cough leak point pressure $(\mathrm{cmH} 2 \mathrm{O})$; Data are presented as mean $\pm \mathrm{SD}$. 
Seo et al.

al prospectively analyzed patients with SUI; LPP was measured at bladder volumes of $150 \mathrm{~mL}$ and $200 \mathrm{~mL}$ to evaluate the usefulness of LPP measurement at the larger bladder volume. $^{12}$ They showed that the addition of LPP at the 200 $\mathrm{mL}$ bladder volume resulted in a $50 \%$ increase in the detection rate of ISD. Furthermore, a number of patients with no evidence of leakage at $150 \mathrm{~mL}$ had a positive LPP at 200 $\mathrm{mL}$. A strong correlation has been reported between the subjective degree of SUI and LPP. ${ }^{21}$ In the present study, we confirmed the previous report that the symptom grade of SUI correlates well with LPP.

Other factors that can affect LPP include the presence of a catheter itself, as well as catheter size. ${ }^{22}$ Observer effect the inability to demonstrate the leakage of urine in the presence of study personnel - is considered another factor. ${ }^{23}$ Bump et al recommended not to judge the urethral function as ISD by the mere application of LPP measurement. ${ }^{18}$ They suggested ISD should be diagnosed with not only LPP, but also with patient history, as well as urodynamic, anatomic, and clinical factors in SUI women. It appears that a practical guideline, including the aforementioned factors, is necessary and standardization of this technique is needed before it is widely used in clinical setting.

This study differs from previous studies in that the LPP was measured with four different bladder volumes in an attempt to improve the precision of the LPP test in each subject. Additional measurements in the same patient may increase the detection rate of SUI when the patient does not generate sufficient Valsalva at the first test and thereby falls into the false negative group. This study could support the previous reports concerning the variability of LPP by bladder volume and relationship between VLPP and CLPP. In the evaluation of continence system in SUI women, measurement of LPP should be carried out with careful attention to these factors that can affect the value.

As a limitation, we could not measure the correlation between age and VLPP or CLPP in this study. Measurement of maximal urethral closure pressure and its correlation with LPP could give additional information regarding the estimation of urethral function in SUI women. Another limitation of this study is that the number of patients included was relatively small.

\section{Conclusion}

LPP induced by cough occurs more frequently than by Valsalva. Both VLPP and CLPP are decreased significantly with bladder filling in women with SUI, and women with severe symptoms of SUI are more likely to have low LPP. This study implies that wide variabilities of LPP measurement by different test environments should be considered when determining urethral function in SUI women.
Competing interests: The authors declare no competing financial or personal interests.

This paper has been peer-reviewed.

\section{References}

1. Abrams $P$, Cardozo $L$, Fall $M$, et al. The standardization of terminology of lower urinary tract function: Report from the Standardisation Sub-committee of the International Continence Society. Standardisation Sub-committee of the International Continence Society. Neurourol Urodyn 2002;21:167-78. http:// dx.doi.org/10.1002/nau.10052

2. Wan J, McGuire EJ, Bloom DA, et al. Stress leak point pressure: A diagnostic tool for incontinent children. J Urol 1993;150:700-2.

3. McGuire EJ, Woodside JR, Borden TA, et al. Prognostic value of urodynamic testing in myelodysplastic patients. J Urol 1981;126:205-9.

4. Kuo HC. Videourodynamic analysis of the relationship of Valsalva and cough leak point pressures in women with stress urinary incontinence. Urology 2003;61:544-8. http://dx.doi.org/10.1016/500904295(02)02500-1

5. Bump RC, Elser DM, McClish DK. Valsalva leak point pressures in adult women with genuine stress incontinence: Reproducibility, effect of catheter caliber, and correlation with passive urethral pressure profilometry. Neurourol Urodyn 1993;12:307-8.

6. Payne CK, Raz S, Barbiaz JW. The Valsalva leak point pressure in the evaluation of stress urinary incontinence: technical aspects of measurement. J Urol 1994;151:478A.

7. Theofrastous JP, Cundiff GW, Harris RL, et al. The effect of vesical volume on Valsalva leak-point pressures in women with genuine stress urinary incontinence. Obstet Gynecol 1996;87:71 1-4. http://dx.doi. org/10.1016/0029-7844(96)00018-X

8. Decter RM, Harpster L. Piffalls in determination of leak point pressure. J Urol 1992;148:588-91.

9. McGuire EJ, Cespedes RD, O'Connell HE. Leak point pressures. Urol Clin North Am 1996;23:253-62. http://dx.doi.org/10.1016/S0094-0143(05)70309-8

10. Miklos JR, Sze EH, Karram MM. A critical appraisal of the methods of measuring leak-point pressures in women with stress incontinence. Obstet Gynecol 1995;86:349-52. http://dx.doi.org/10.1016/00297844(95)00173-0

11. Peschers UM, Jundt K, Dimpfl T. Differences between cough and Valsalva leak point pressure in stress incontinent women. Neurourol Urodyn 2000;19:677-81. http://dx.doi.org/10.1002/15206777(2000) 19:6<677::AID-NAU5>3.0.C0;2-J

12. McLennan MT, Melick CF, Bent AE. Leak-point pressure: Clinical application of values at two different volumes. Int Urogynecol J Pelvic Floor Dysfunct 2000;11:136-41. http://dx.doi.org/10.1007/ s001920070040

13. Stamey TA. Endoscopic suspension of the vesical neck for urinary incontinence in females. Report on 203 consecutive patients. Ann Surg 1980;192:465-71. http://dx.doi.org/10.1097/00000658198010000-00005

14. Bump RC, Mattiasson A, Bo K, et al. The standardization of terminology of female pelvic organ prolapse and pelvic floor dysfunction. Am J Obstet Gynecol 1996;175:10-7. http://dx.doi.org/10.1016/S00029378(96) 70243-0

15. Abrams P, Blaivas IG, Stanton SL, et al. The standardization of terminology of lower urinary tract function. The International Continence Society Committee on Standardization of Terminology. Scand I Urol Nephrol Suppl 1988;1 14:5-19.

16. McGuire EJ, Lytton B, Kohorn El, et al. The value of urodynamic testing in stress urinary incontinence. J Urol 1980;124:256-8. http://dx.doi.org/10.1016/0090-4295(80)90438-0

17. McGuire EJ, Fitzpatrick CC, Wan J, et al. Clinical assessment of urethral sphincter function. J Urol 1993;150:1452-4

18. Bump RC, Elser DM, Theofrastous JP, et al. Valsalva leak point pressures in women with genuine stress incontinence: Reproducibility, effect of catheter caliber, and correlations with other measures of urethral resistance. Continence Program for Women Research Group. Am J Obstet Gynecol 1995; 173:551-7. http://dx.doi.org/10.1016/0002-9378(95)90281-3

19. DeLancey JOL. Structural aspects of urethrovesical function in the female. Neurourol Urodyn 1988;7:50919. http://dx.doi.org/10.1002/nau.1930070602

20. DeLancey JOL. Structural support of the urethra as it relates to stress urinary incontinence: The hammock hypothesis. Am J Obstet Gynecol 1994;170:1713-20. http://dx.doi.org/10.1016/S00029378(12)91840-2 
21. Nitti VW, Combs AJ. Correlation of Valsalva leak point pressure with subjective degree of stress urinary incontinence in women. J Urol 1996;155:281-5. http://dx.doi.org/10.1016/S0022-5347(01)666199

22. Maniam $P$, Goldman HB. Removal of transurethral catheter during urodynamics may unmask stress urinary incontinence. J Urol 2000; 167:2080-2. http://dx.doi.org/10.1016/S0022-5347(05)65089-6

23. Faerber GJ, Vashi AR. Variations in Valsalva leak point pressure with increasing vesical volume. J Urol 1998;159:1909-11. http://dx.doi.org/10.1016/S0022-5347(01)63192-6
Correspondence: Dr. Sun-Ouck Kim, Department of Urology, Chonnam National University Hospital and Medical School, South Korea; seinsena@hanmail.net 